\title{
Klebtechnische Erfindungen ausgezeichnet
}

Die internationale Fachmesse „Ideen - Erfindungen - Neuheiten“ iENA 2012 in Nürnberg verlief für die Thüringer Hochschulen und Institute, insbesondere im Hinblick auf die Prämierung innovativer Entwicklungen ihrer Wissenschaftler, sehr erfolgreich: Sie errangen eine Gold-, vier Silber- und eine Bronzemedaille. Zwei dieser prämierten Innovationen stammen aus der Klebtechnik.

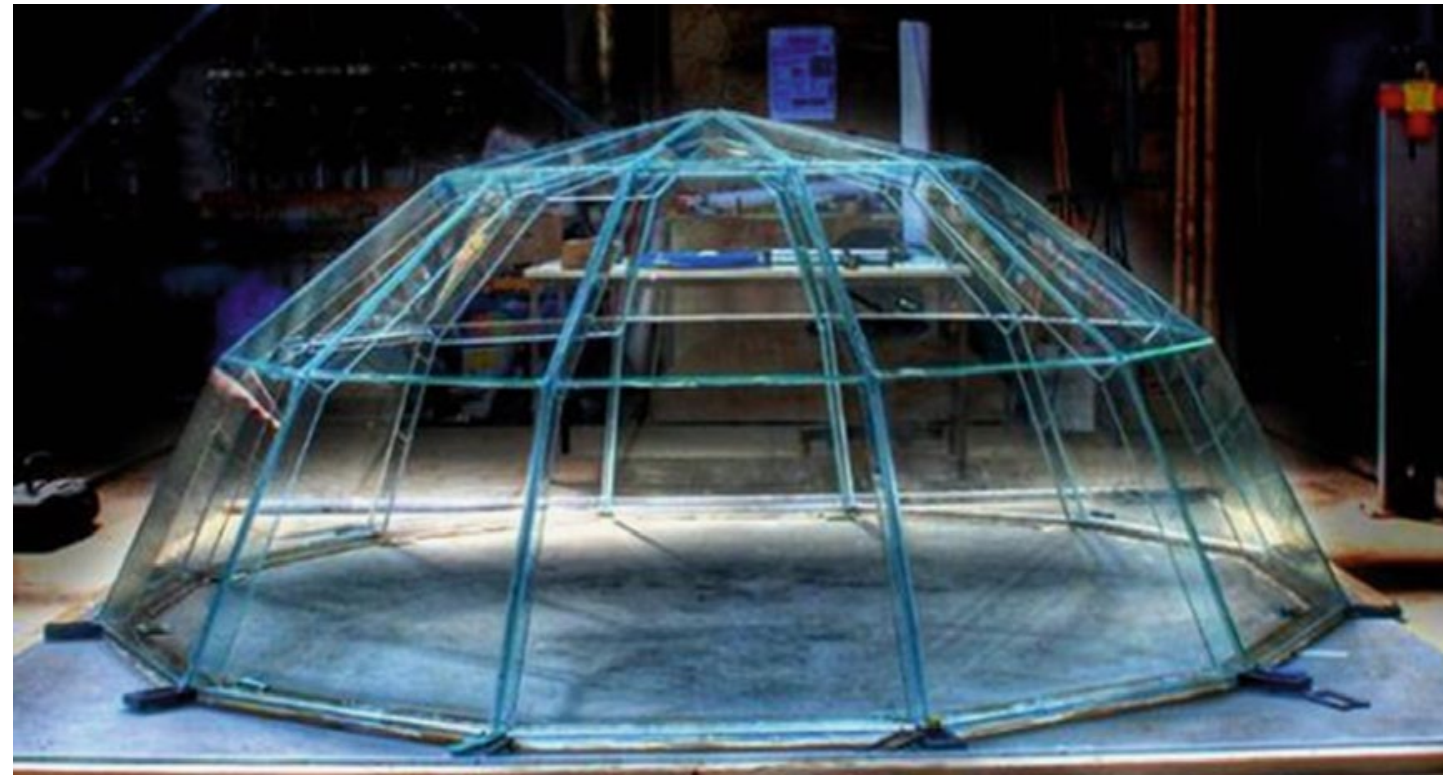

Beispiel einer „geklebten“ Glaskuppel (Bildquelle: Bauhaus-Universität Weimar/Holm Friedrich)
Forschungsprojekt „Vorrichtung und Verfahren zur Überwachung des Zustandes von Klebverbindungen“. Bei dieser Erfindung handelt es sich um ein faseroptisches Sensorsystem, das tragende Klebverbindungen, z. B. in Fassadenelementen, während des gesamten Lebenszyklus von der Aushärtung bis zum Nutzungsen-

B esonders hervorzuheben ist eine Goldmedaille, die sowohl nach Ilmenau als auch nach Weimar ging. Mit ihr wird eine gemeinsame Erfindung von Dr. Bernd Halbedel, TU IImenau, und Prof. Jörg Hildebrand, Bauhaus-Universität Weimar, prämiert. Das erfolgreiche Forschungsprojekt beider Wissenschaftler „Ferrimagnetische Partikel, Klebstoff und Verfahren zu deren Herstellung“ ermöglicht die steuerbare Aushärtung von Spezialklebstoffen und macht ein Versagen des Klebstoffs an seinen Grenz- flächen kontrollierbar. Die Anwendung erfolgt im Rahmen von Reparatur- und Rückbauzwecken von Verglasungselementen bei Ganzglas- und Stahl-GlasFassadenverklebungen.

Eine weitere klebtechnische Gemeinschaftserfindung wurde mit einer Silbermedaille geehrt:

Prof. Jörg Hildebrand, Bauhaus-Universität Weimar, und Dr. rer. nat. Michael Kuhne, Materialforschungs- und Prüfanstalt an der Bauhaus-Universität Weimar, erhielten sie für das erfolgreiche de direkt überwacht. Dabei werden die Temperaturen und die Dehnungen zerstörungsfrei und unabhängig von der Bauteilgröße gemessen und ausgewertet.

Die internationale Fachmesse iENA fand als Forum für die internationale Vermarktung von Erfindungen und neuen Produkten zum 64. Mal statt. In diesem Jahr präsentierten Aussteller aus 34 Ländern 750 Erfindungen und neue Produktideen. Sie decken ein breites Spektrum von praktischen Dingen für den Alltag bis hin zu Hightech-Lösungen ab.

\section{Bodo Möller und Huntsman veranstalten Klebstoffseminar}

D e Unternehmen Bodo Möller Chemie und Huntsman Advanced Materials setzen am 25. April 2013 ihre Reihe branchenübergreifender Klebstoffseminare unter dem Titel „Kleben als moderne Fügetechnologie“ fort. In diesem Jahr präsentieren die Klebstoffexperten die erhöhte Konstrukti- onsfreiheit und Innovationskraft moderner Klebstoffe - etwa bei der Nutzung neuartiger Werkstoffe. Im Laufe des Seminars werden aktuelle und künftige Anwendungen von Klebstoffen als Verbindungstechnik für Metall, Kunststoffe und Hybridteile mit technischen Vorträgen, Produktpräsentati- onen, Workshops und Fallstudien vorgestellt.

Dieses Seminar richtet sich an Interessenten, die Klebstoffe als innovative Technologie kennenlernen oder auch vorhandene Kenntnisse vertiefen wollen.

Weitere Infos: www.bm-chemie.de 